\title{
The Role of Conformity in Relation to Cohesiveness and Intimacy in Day-Hospital Groups of Patients with Schizophrenia
}

\author{
II Ho Park', Sun Young Park², Sulkee Choi ${ }^{2}$, Soo Young Lee ${ }^{3}$, and Jae-Jin Kim ${ }^{2,4} \bowtie$ \\ ${ }^{1}$ Department of Psychiatry and Behavioral Neurosciences, International St. Mary's Hospital, Catholic Kwandong University, Incheon, \\ Republic of Korea \\ ${ }^{2}$ Institute of Behavioral Science in Medicine, Yonsei University College of Medicine, Seoul, Republic of Korea \\ ${ }^{3}$ Department of Psychiatry, Cheil General Hospital, Dankook University College of Medicine, Seoul, Republic of Korea \\ ${ }^{4}$ Department of Psychiatry, Yonsei University College of Medicine, Seoul, Republic of Korea
}

\begin{abstract}
Objective Conformity is defined as the act of adjusting one's behavior to match the social responses of others. Patients with schizophrenia often adjust their maladaptive behaviors by conforming in group treatment settings. This study aimed to examine whether the opinions of group members influence conformity of patients with schizophrenia who attend day-hospital programs.

Methods Nineteen patients with schizophrenia from four different day-hospital programs and 23 healthy controls from four different social clubs completed the homographic meaning choice task under conditions of prior exposure to the pseudo-opinions of their group members, strangers, and unknown information sources. Group influences on conformity were observed when the level of group cohesiveness was high and the level of intimacy was low across participant groups.

Results Controls did not exhibit a significant effect of group influence on conformity, whereas patients were significantly influenced by their group members when making conformity-based decisions despite significantly lower intimacy and cohesiveness levels.

Conclusion These findings suggest that unlike controls, patients with schizophrenia tend to respond with conformity when influenced by the opinions of their affiliated group. In patients with schizophrenia group conformity may be used to select a more accurate decision and to enhance feelings of affiliation among them.

Psychiatry Investig 2017;14(4):463-470
\end{abstract}

Key Words Conformity, Group cohesiveness, Intimacy, Schizophrenia, Group therapy.

\section{INTRODUCTION}

Although patients with schizophrenia recover from acute symptoms, they often face deficits in social functioning. Disruptions in social cognition, including theory of mind and emotional processing, have been reported to contribute to the deterioration of social functioning among patients with schizophrenia. ${ }^{1-3}$ Social skills training has been performed as one of the beneficial approaches in improving social functioning in patients with schizophrenia. ${ }^{4,5}$ The majority of social rehabilitation programs for patients with schizophrenia take place in group environments, including "day-hospitals," where

Received: March 31, 2016 Revised: May 30, 2016

Accepted: July 5, 2016 Available online: May 16, 2017

$\triangle$ Correspondence: Jae-Jin Kim, MD, PhD

Department of Psychiatry, Yonsei University Gangnam Severance Hospital, 211 Eonju-ro, Gangnam-gu, Seoul 06273, Republic of Korea

Tel: +82-2-2019-3341, Fax: +82-2-3462-4304, E-mail: jaejkim@yonsei.ac.kr

(a) This is an Open Access article distributed under the terms of the Creative Commons Attribution Non-Commercial License (http://creativecommons.org/licenses/bync/4.0) which permits unrestricted non-commercial use, distribution, and reproduction in any medium, provided the original work is properly cited. patients learn and practice socially adaptive behaviors. Psychiatric patients in group therapy often alter maladaptive behaviors through conformity based on interpersonal learning, group pressure and identification with others in the context of acceptance, support and trust provided by group cohesion. ${ }^{6}$

Conformity is the act of adjusting one's behavior to match the social responses of others. Individuals conform when they appreciate the values of their social groups. Individuals may also conform when motivated to affiliate with a social group, to acquire a positive self-image, or to consider group opinions to be more reliable and accurate than their own. ${ }^{7}$ Conformity can be observed in subconscious interpersonal behaviors of mimicry which assist in building rapport, promoting intimacy and consequently achieving affiliation. ${ }^{8}$ Individuals often consciously conform to gain social approval and to build rewarding relationships with group members. ${ }^{7}$ Thus, conformity is an intrinsically motivated process and may be pursued or resisted depending on the context of decision making.

Patients with schizophrenia are less likely to get married or to form meaningful long-term relationships. This difficulty in 
relating to others may arise from deficits in social cognition and neurocognition as well as from negative symptoms. ${ }^{9}$ When patients with schizophrenia interact within a group, the presence of cognitive impairments and negative symptoms may impede the development of group cohesiveness, intimacy and sensitivity to group pressures, and thus they may display abnormal conformity behaviors. However, the mechanism underlying these behavioral changes and the relationship of these behavioral changes with influences of group affiliation are not well understood.

This study aimed to explore whether or not the role of affiliated group opinions in conformity is impaired in patients with schizophrenia. For this purpose, the effect of cohesiveness and intimacy on conformity-based decision making was compared between patients with schizophrenia who attended a day-hospital program and normal controls. We hypothesized that patients with schizophrenia would be less likely to conform to the opinions of their affiliated group due to the lower level of cohesiveness and intimacy within their group.

\section{METHODS}

\section{Participants}

Participants were recruited in 5 to 7 numbers in a social group to evaluate an interaction between group members. Twenty-two patients with schizophrenia who were attendees of the 4 different day-hospitals participated in this study. All patients met the DSM-IV-TR (American Psychiatric Association 2000) ${ }^{10}$ criteria for schizophrenia without the presence of comorbid psychiatric disorders. Three patients were excluded due to difficulties in sustaining attention during completion of the task or due to difficulties understanding the task instruc- tions, and data for the remaining 19 patients ( 9 males/10 females, $31.5 \pm 8.7$ years old) were analyzed. Symptom severity scores for the patients, assessed with the Positive and Negative Syndrome Scale ${ }^{11}$ and scored based on the five-factor model by van der Gaag et al. ${ }^{12}$ were $15.7 \pm 5.0$ for positive symptoms, $18.6 \pm 7.0$ for negative symptoms, $22.4 \pm 5.4$ for disorganization, $13.3 \pm 3.3$ for excitement, and $16.5 \pm 5.4$ for emotional distress. Eleven patients were on a single atypical antipsychotic, 6 patients on one atypical and one typical antipsychotics and 2 patients on two atypical antipsychotics. Among these patients, 7 patients were additionally taking antidepressants.

Control participants were 23 healthy volunteers ( 12 males/ 11 females, $29.3 \pm 7.2$ years old), who belonged to one of the 4 different social clubs and had no current or past psychiatric disorders. Participants who had past or present neurological disorders or significant medical conditions were excluded. The patient and control groups showed no significant difference in age and sex, but education years were significantly shorter in patients than in controls $(13.1 \pm 1.7$ and $15.1 \pm 2.0$, respectively; $\mathrm{t}=-3.47, \mathrm{p}<0.01)$. This study was carried out under the protocols approved by the institutional review board of Yonsei University Severance Mental Health Hospital, and written informed consent was obtained from all participants.

\section{Experimental task}

All participants took part in the pre-experiment survey before performing the homographic meaning choice task as a main experiment. In order to induce group cohesiveness, they participated in the survey in groups of four to five in the same party. In this survey, 99 word sets consisting of a homograph and two category words that represented its different meanings of lower and higher usages were presented to participants,

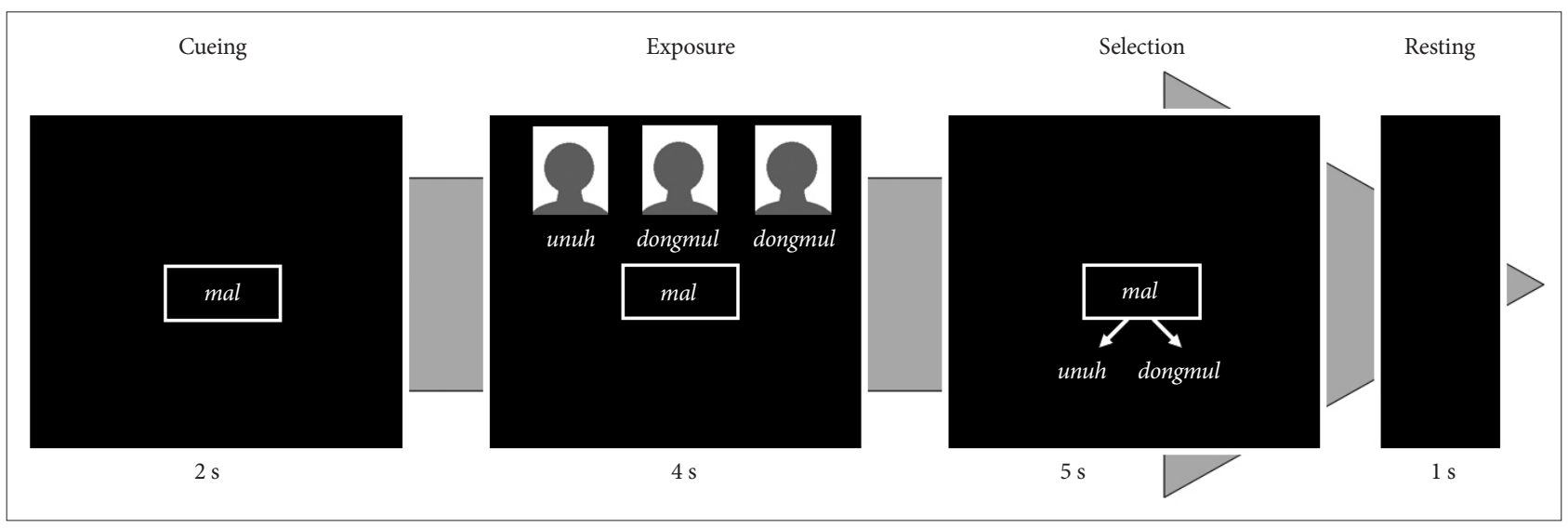

Figure 1. An example of visual stimuli presented in serial trials of the homographic meaning choice task. A homograph (Korean pronunciation 'mal' means "speech" or "horse") was presented in the cueing phase, and photographs of three others and their choice of which one between the two categories corresponds to the more frequently used meaning of the cue word (Korean pronunciation "unuh" and "dongmul" means "language" and "animal", respectively) were presented in the exposure phase. Korean words were used in the real experiment, but they were replaced with Korean pronunciations in this figure for better understanding. The three others were all group members, strangers, or outlined person shapes according to the task condition. In the selection phase, the two categories were presented, and participants were asked to consider the others' opinions and choose between the two according to their own opinion. 
and they were asked to choose a category word according to their own decision about which meaning is more frequently used. The homographs were selected from the word list reported in the 2002 survey of usage frequency of modern Korean language, ${ }^{13}$ in which usage frequencies were estimated by counting each word when used in selected references, which included texts, cultural books, literary works, journals, scripts, and recorded audio materials during the 1990s in South Korea. We selected the homographs that contained a word meaning with lower usage of at least 10 counts and another word meaning with higher usage of at least 10 additional counts. In addition, black and white facial photographs were taken with a neutral expression to use in the main experiment.

The main experiment - homographic meaning choice task -consisted of 99 trials with 4 different phases such as cueing, exposure, selection, and resting (Figure 1), in which visual stimuli were presented on a 19-inch LCD monitor. In the cueing phase, for $2 \mathrm{sec}$, a homograph was presented as a cue in the center. In the exposure phase, for $4 \mathrm{sec}$, photographs of three others and their choice of the category word which they thought to be more frequently used meaning of the cue word were presented above the cue. The others were group members, strangers, or outlined person shapes. All photographs for group members and strangers were facial pictures with neutral emotion. The three different conditions were used to distinguish affiliated group influences from non-affiliated social and informational influences, and each condition included 33 sets. The category words were set up to maintain an incongruent-to-congruent ratio of 18:15 with the participant's pre-experiment response to the homograph regardless of the opinions of others in the pre-experiment survey, and their order of presentation was counterbalanced for each condition. In the selection phase, the two categories were presented under the cue for $5 \mathrm{sec}$, and participants were asked to consider the others' opinions in the prior exposure phase and choose between the two according to their own opinion by pressing the left or right mouse button. In the resting phase, a blank screen was presented for $1 \mathrm{sec}$.

\section{Debriefing assessment of intimacy, group cohesiveness and paranoia}

As a debriefing questionnaire, group intimacy was assessed by asking participants to rate a feeling of intimacy with each of other group members whose photograph and pseudo-opinion appeared during the experimental task on a Likert scale of 1 (not at all intimate) to 5 (very intimate). The sum of intimacy rating for each of the three group members was used as the intimacy score.

Cohesiveness within each group was measured using the Group Cohesiveness Scale (GCS) which was composed of 17 items modified from the cohesiveness dimension of the Working Alliance Inventory. ${ }^{14}$ The items were related to group acceptance, group atmosphere and group participation, and scored by a 5-point Likert scale in which greater scores represent greater group cohesiveness. In addition, to assess the paranoid tendencies that may influence individuals' attitudes and responses to others, all participants were required to complete the Paranoia Scale. ${ }^{15}$

\section{Statistical analysis}

Assuming that intimacy and group cohesiveness are important factors in influencing conformity, participants were categorized into the low and high intimacy groups according to median intimacy scores, and into the low and high cohesiveness groups according to median GCS scores. The conforming response was defined as a change from the original opinion to the incongruent opinion after the exposure, and its rate was calculated by dividing the number of the conforming responses by the total number of trials using the incongruent opinions. The opposing response was defined as a change from the original opinion to the congruent opinion after the exposure, and its rate was calculated by dividing the number of the opposing responses by the total number of trials using the congruent opinions. As participants presenting high rates of both the conforming and opposing responses cannot be considered truly conforming, opposing response rate was taken into account to calculate the conformity tendency; the conformity tendency was calculated by subtracting the opposing response rate from the conformity response rate. To control the effect of informational influences on the conformity tendency, the conformity tendency in the outlined human shape condition was subtracted from that in the group member or stranger condition, resulting in the degree of social influence.

Repeated measures analysis of variance and multivariate analysis of covariance were conducted using the participant group status, group intimacy level and group cohesiveness level as independent variables and years of education as a covariate. These analyses examined the effect of the opinion sources (i.e., group members, strangers and outlined human shapes), subject groups (patients and controls) and the levels of intimacy and group cohesiveness on the conforming response rate, the degree of social influence (i.e., group members and strangers) on the conformity tendency and the degree of others' influence (i.e., group members, strangers and outlined human shapes) on response time. Statistical analyses were conducted with a significance level of $\mathrm{p}<0.05$. 


\section{RESULTS}

\section{Debriefing assessments}

The median intimacy scores were 9 (interquartile range, $3.75-10$ ) in patients and 12 (interquartile range, 10-12) in controls. The median GCS scores in patients and controls were 54 (interquartile range, 50-64) and 63 (interquartile range, 5768 ), respectively. The intimacy and GCS scores were significantly lower in patients than in controls (Mann-Whitney $\mathrm{U}=$ 46, $\mathrm{p}<0.001$; Mann-Whitney $\mathrm{U}=124, \mathrm{p}=0.006$, respectively). Since the median intimacy and GCS scores for all participants were 10 and 59, respectively, participants were classified into the low $(\leq 10)$ and high $(>10)$ intimacy groups, and the low $(\leq 59)$ and high $(>59)$ cohesiveness groups. Patients showed greater paranoia scale scores at the marginal significance than controls (Table 1). In addition, the PANSS positive symptom scores were negatively correlated with the GCS scores ( $r=-0.61$, $\mathrm{p}=0.005$ ), and the negative symptom scores were negatively correlated with the intimacy scores $(\mathrm{r}=-0.48, \mathrm{p}<0.05)$.

\section{Conforming response rate and group influence on the conformity tendency}

The conforming response rate in each opinion source condition showed no significant group difference (Table 2). Neither opinion source nor its interaction effects with the subject group, intimacy level, or group cohesiveness level significantly affected the conforming response rates. Moreover, both the intimacy effect and group cohesiveness effect, as well as the subject group-by-intimacy and subject group-by-group cohesiveness interaction effect on the conforming response rates were statistically insignificant.

The degree of social influence on the conformity tendency exhibited a significant main effect of subject group $(\mathrm{df}=2, \mathrm{~F}=$ $6.92, \mathrm{p}=0.003$ ) and a significant interaction effect of subject group-by-opinion source $(\mathrm{df}=1, \mathrm{~F}=7.40, \mathrm{p}=0.01)$. As depicted in Figure 2A, post-hoc analysis revealed that greater group members-than-strangers' influence was observed only in patients $(\mathrm{df}=18, \mathrm{t}=3.08, \mathrm{p}=0.006)$ and group members' influence was greater in patients than in controls $(\mathrm{df}=38.3, \mathrm{t}=2.80, \mathrm{p}=$ 0.008). Interaction effects of intimacy-by-opinion source and group cohesiveness-by-opinion source, and the main effects of intimacy and group cohesiveness were not significant. How-

Table 1. Demographic and clinical characteristics

\begin{tabular}{|c|c|c|c|c|}
\hline & Schizophrenia $(\mathrm{N}=19)$ & Control $(\mathrm{N}=23)$ & $\chi^{2} / \mathrm{t}$ & $\mathrm{p}$ \\
\hline Gender, male/female* & $9 / 10$ & $12 / 11$ & 0.10 & 0.76 \\
\hline Age, years ${ }^{\dagger}$ & $31.5 \pm 8.7$ & $29.3 \pm 7.2$ & -0.93 & 0.36 \\
\hline Years of education ${ }^{\dagger}$ & $13.1 \pm 1.7$ & $15.1 \pm 2.0$ & 3.47 & 0.001 \\
\hline Intimacy, low $(\leq 10) /$ high $(>10)^{*}$ & $15 / 3$ & $6 / 17$ & 13.2 & $<0.001$ \\
\hline GCS score, low $(\leq 59) /$ high $(>59)^{*}$ & $14 / 5$ & $7 / 16$ & 7.79 & 0.005 \\
\hline Paranoia Scale score ${ }^{\dagger}$ & $43.4 \pm 13.8$ & $36.4 \pm 9.3$ & -1.93 & 0.06 \\
\hline
\end{tabular}

${ }^{*}$ number, ${ }^{\dagger}$ mean \pm standard deviation. GCS: Group Cohesiveness Scale

Table 2. The means and standard errors of the conforming and opposing response rates in each opinion source condition and the results of the multivariate analysis of covariance

\begin{tabular}{|c|c|c|c|c|c|}
\hline & Schizophrenia $(\mathrm{N}=19)$ & Control $(\mathrm{N}=23)$ & $\mathrm{df}$ & $\mathrm{F}$ & $\mathrm{p}$ \\
\hline Conforming response rate & & & 2 & 1.67 & 0.19 \\
\hline Group members & $0.485(0.038)$ & $0.394(0.045)$ & & & \\
\hline Strangers & $0.368(0.034)$ & $0.412(0.041)$ & & & \\
\hline Outlined person shapes & $0.404(0.043)$ & $0.403(0.042)$ & & & \\
\hline Opposing response rate & & & 2 & 2.25 & 0.10 \\
\hline Group members & $0.243(0.038)$ & $0.154(0.021)$ & & & \\
\hline Strangers & $0.274(0.045)$ & $0.162(0.024)$ & & & \\
\hline Outlined person shapes & $0.257(0.048)$ & $0.113(0.018)$ & & & \\
\hline Conforming response time (ms) & & & 3 & 1.55 & 0.22 \\
\hline Group members & $2,195(215)$ & $1,683(165)$ & & & \\
\hline Strangers & $2,576(222)$ & $1,777(171)$ & & & \\
\hline Outlined person shapes & $2,446(250)$ & $1,844(192)$ & & & \\
\hline
\end{tabular}


ever, significant interaction effect of intimacy-by-group cohesiveness was found in the degree of group members' influence $(\mathrm{df}=2, \mathrm{~F}=3.50, \mathrm{p}=0.04)$. As depicted in Figure $2 \mathrm{~B}$, post-
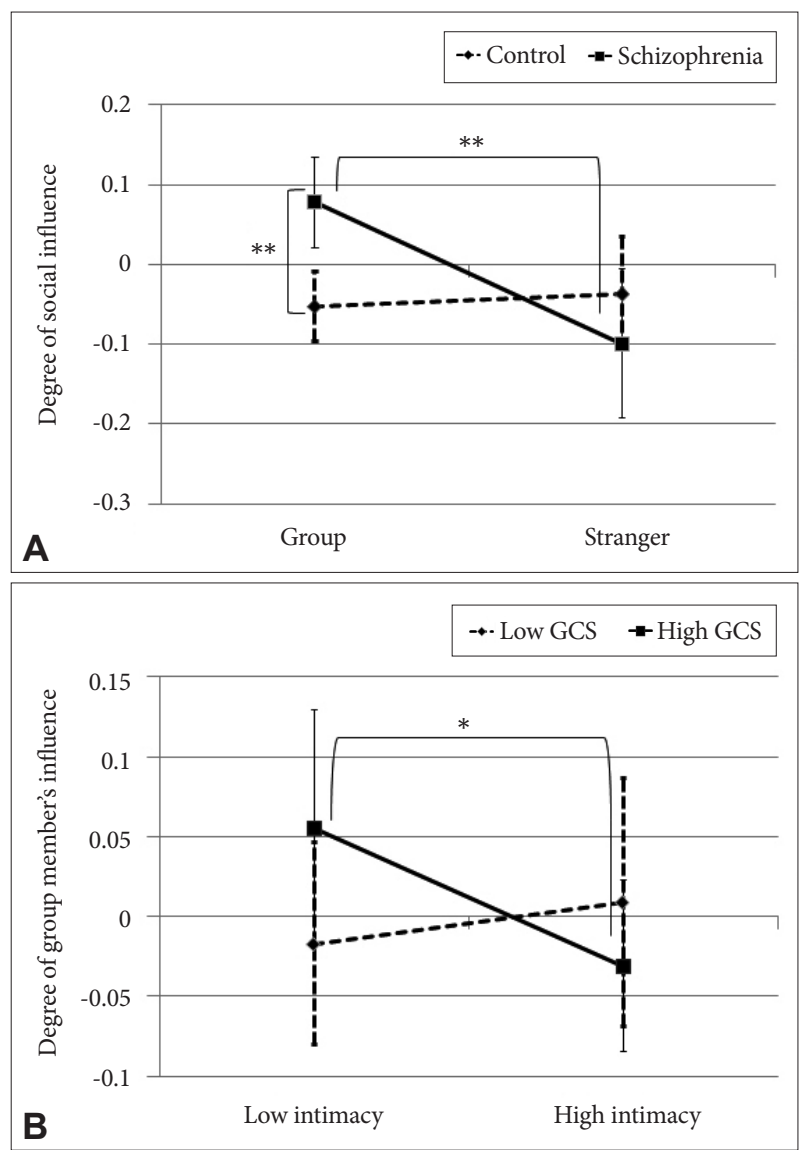

Figure 2. The estimated means and standard errors of the degree of social influence on the conformity tendency. A: Group members' influence was significantly greater than strangers' influence in patients and was greater in patients than in controls. B: Group members' influence was significantly greater than strangers' influence when the intimacy level was lower in participants with higher level of Group Cohesiveness Scale (GCS) scores. ${ }^{*} p<0.05,{ }^{* *} p<0.01$. hoc test revealed that the degree of group members' influence was significantly greater for the low than high levels of intimacy in participants with high GCS scores $(\mathrm{df}=19, \mathrm{t}=2.12$, $\mathrm{p}<0.05)$.

No significant correlation was found between the conforming response rates and the PANSS factor scores. However, a marginal significance was found between the PANSS disorganization scores and the conforming response rate to strangers $(\mathrm{r}=0.46, \mathrm{p}=0.05)$. The degree of group influence did not significantly correlate with any PANSS factor scores. The conforming response rates and the degree of group influence were not significantly correlated with years of education, and showed no significant difference according to the type of antipsychotics or the status of antidepressant use in patients.

\section{Conforming response time}

Neither the main effect of opinion sources nor its interaction effects with intimacy and group cohesiveness on the conforming response times were significant. There was no significant subject group or intimacy effect on conforming response times, but the significant main effect of group cohesiveness was found to be significant $(\mathrm{df}=3, \mathrm{~F}=2.94, \mathrm{p}<0.05)$. As depicted in Figure 3, post-hoc analyses revealed that individuals with the high GCS scores (>59) showed significantly slower conforming response to the opinions of strangers and outlined person shapes after exposures than individuals with the low GCS scores $(\leq 59)(\mathrm{df}=1, \mathrm{~F}=5.32, \mathrm{p}=0.03 ; \mathrm{df}=1, \mathrm{~F}=6.82, \mathrm{p}=0.01$, respectively), but not to group members' opinions after exposure. In addition, there were no significant interaction effects of subject group $\mathrm{x}$ intimacy and subject group $\mathrm{x}$ group cohesiveness. No PANSS factor scores were significantly correlated with the conforming response times.

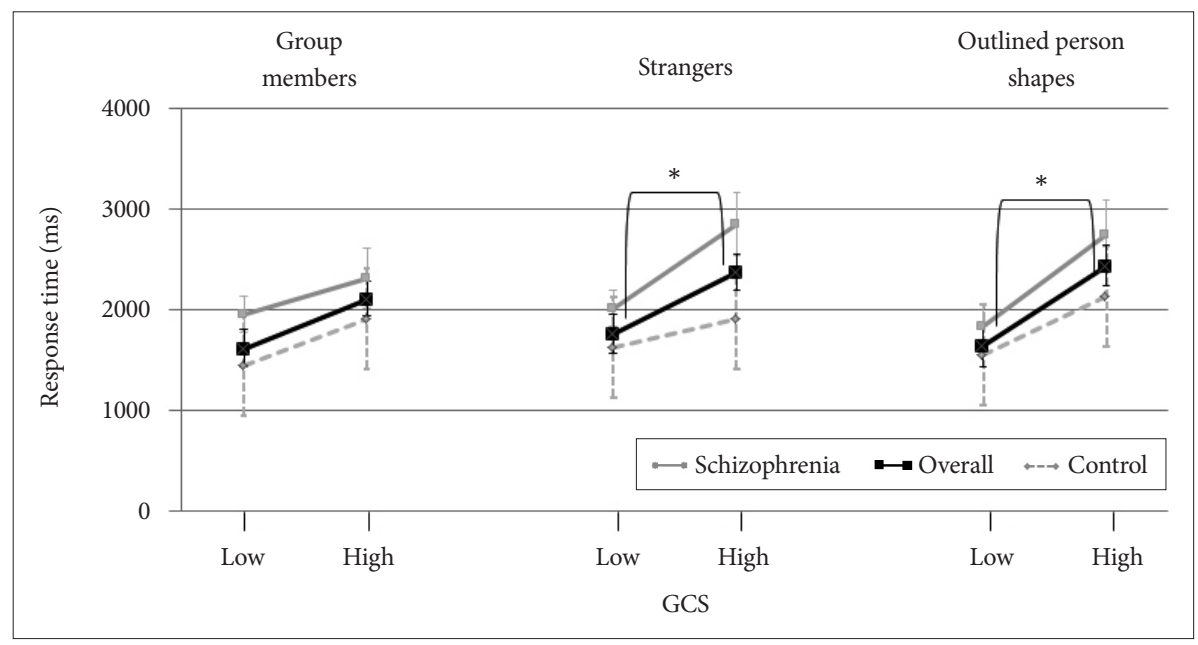

Figure 3. The effect of group cohesiveness on conforming response time. The higher level of Group Cohesiveness Scale (GCS) scores was associated with significantly slower conforming response time after exposures to strangers' and outlined person shapes' opinions than the lower level of group cohesiveness, but not after exposure to group members' opinions. * $p<0.05$. 


\section{DISCUSSION}

In this study, conformity-based decision making was examined as it relates to intimacy and cohesiveness properties of the affiliated group among patients with schizophrenia. Across both patients and control participants, interaction effects between intimacy and cohesiveness were observed. That is, participants with a lower level of cohesiveness were less influenced by group opinions regardless of the intimacy level, whereas participants with a higher level of group cohesiveness were influenced by group opinions when the intimacy level was low. Additionally, the time to make conformity-based decisions differed according to the level of cohesiveness. Specifically, participants with a higher level of cohesiveness were slower in conforming to the opinions of strangers and unknown sources. These findings suggest that participants were more cautious to conform to non-group opinions when group cohesiveness was high. Contrary to our hypothesis, there was a significant influence of the affiliated group opinion on the conformity tendency among patients with schizophrenia, but not among healthy controls. This effect was found despite the fact that patients with schizophrenia had the lower level of intimacy and cohesiveness within their affiliated group.

Our results indicate that the degree of group members' influence was significantly lower for the high than low levels of intimacy in participants with the higher level of cohesiveness. Although healthy controls perceived the greater level of intimacy and cohesiveness in their affiliated group, they were less influenced by the opinions of their group members. Two aspects of conformity such as informational and normative conformity have been associated with motivation. Informational conformity is based on the desire to form accurate interpretations of reality, whereas normative conformity is based on the goal of obtaining the social approval of others. A prior study of racial minorities demonstrated that the prospect of not fitting in with one's group may compel individuals to conform in order to strengthen their affiliation. ${ }^{16}$ Accordingly, individuals who maintain intimate relationships within their affiliated group may be at a reduced risk of being excluded from his or her group. Thus, these individuals would be able to make more independent decisions with fewer affiliative constraints. Interestingly, among participants with a lower intimacy level, the influence of group on the conformity tendency was more likely to be observed when the level of group cohesiveness was higher. This suggests that an individual's need for social affiliation may arise when the individual does not feel an intimate connection with other members of an otherwise cohesive group. Alternatively, the failure to observe conformity in healthy controls may be due to the emphasis on making an accurate decision within this group. Although not stated in the task instructions, participants were aware that they were participating in a study of decision making, and participants were led to believe that the accuracy of their performance on the task would be assessed. However, if participants regarded the exposure to the opinions of others as distractions, they might have attempted to use the strategy of making independent decisions to complete the task.

Another interesting result was that group influence on conformity-based decisions was greater in patients with schizophrenia than in healthy controls. This finding was true despite the reduced level of intimacy and cohesiveness within the affiliated group of patients. The results showed that participants with a lower level of intimacy and group cohesiveness were less likely to be influenced by the opinions of the group members. When an individual is less intimate with the members of his or her group, his or her need for affiliation increases and conformity becomes a way of gaining the approval of the group. However, when cohesiveness among group members is weaker, a person may sense a weaker effort within the group and as such, individuals in these groups may not rely on conformity to strengthen their affiliation. Furthermore, it has been shown that when the perceived level of consensus within a group is lower, an individual becomes less confident of the accuracy of one's intergroup beliefs. ${ }^{17}$ Thus, individuals who are less intimate with the members of a less cohesive group may rely less on group opinion. Patients with schizophrenia displayed a lower level of both intimacy and group cohesiveness; however, individuals in this group were more influenced by group opinion. That is, despite a lower level of group intimacy that may have increased the needs for affiliation of members of this group, a lower level of group cohesiveness did not mitigate group influence among the patients.

This finding indicating a greater group influence on conformity among patients with schizophrenia may be explained in relation to low self-esteem. Although it has been suggested that deviating from the attitudes and actions of others may invoke a sense of a unique personal identity, ${ }^{18-20}$ other studies have reported that identifying with and conforming to a valued group can help an individual to maintain positive self-esteem. ${ }^{21,22}$ Affiliative motives driving one to conform to the beliefs and behaviors of others may arise from the need to enhance, protect, or repair one's self-esteem. ${ }^{7}$ Patients with schizophrenia who show predominantly negative symptoms and who are affected by stigma have been reported to have low self-esteem. ${ }^{23,24}$ They also often have had negative experience of being excluded from the majority group. ${ }^{25}$ Therefore, patients participating in day-hospital programs may have greater affiliative motives to conform.

Meanwhile, a theory of social psychology has emphasized the cognitive significance of conformity as a means to main- 
tain a sense of group identity and reduce uncertainty when faced with group conflict. ${ }^{26}$ Based on self-categorization of social identity, individuals engage in attitude changes only when they identify with the source pressuring for change, and this effect has been demonstrated in prior studies irrespective of majority or minority influence. ${ }^{26,27}$ Some studies showed that members of anonymous groups were more likely to follow group norms than members of identifiable groups, suggesting that conformity can depend on cognitive processes and not entirely on concerns of self-presentation and fear of group disapproval. ${ }^{28}$ In this point of view, the greater group influence on conformity observed in the patient group may indicate that the strategic process of conformity is intact. However, the group influence on conformity observed in the context of weak group cohesiveness suggests that the process of group conformity in patients with schizophrenia may not be moderated by the cognitive processes of group identification.

Alternatively, cognitive dysfunctions can be associated with the group influence observed in patients. The results of this study showed that patients were influenced by the opinions of their own group, indicating that patients with schizophrenia were able to selectively attend to external information in the experimental social context. Patients with schizophrenia have been found to have difficulty in independent thinking, decision making and modulating emotional interference that are associated with prefrontal dysfunction. ${ }^{29-32}$ A number of studies have shown that individuals who were primed with words or associations conceptually related to conformity were more likely to conform to the judgments of the group. ${ }^{33,34}$ Moreover, conflicts with group opinion have been shown to trigger neural signals similarly to prediction error which leads to behavioral adjustment in the neuroscientific model of reinforcement learning. ${ }^{35}$ Therefore, top-down cognitive control of social influence is needed for optimal decision making. Healthy controls in this study were not influenced by the group opinions, suggesting that they may have consciously inhibited the effect of group influence in order to make independent decisions. On the other hand, since patients with schizophrenia have been reported consistently to have difficulties in controlling cognitive interferences, ${ }^{36}$ they might not have been able to effectively block the interference of the external information provided.

There are some limitations in the current study. First, the sample size was relatively small because of the condition that patients had to attend a day hospital. Second, it is unclear whether the feeling of intimacy was well measured by the intimacy score because this method was not standardized. Finally, self-esteem may have an important impact on conformity; but this factor was not assessed in this study.

In conclusion, this study examined the role of group influ- ence on conformity during decision making among patients with schizophrenia. While healthy controls were not influenced by their affiliated group opinions, patients with schizophrenia showed greater tendency to respond with conformity when influenced by the opinions of their affiliated group. These findings suggest that, despite the known cognitive deficits in selective attention and decision making associated with this disease, group conformity may be used to select a more accurate decision and to enhance feelings of affiliation and self-esteem among patients with schizophrenia. However, social cognitive processes may be deficient among this group with respect to using conformity-based processes to enhance identification with their affiliated group. The results of this study facilitate the understanding of social behavior in patients with schizophrenia.

\section{Acknowledgments}

This study was supported by the National Research Foundation of Korea (NRF) grant funded by the Korea government (MEST) (No. NRF-2013 R1A2A2A03068342).

\section{REFERENCES}

1. Sergi M, Green M. Social perception and early visual processing in schizophrenia. Schizophr Res 2003;59:233-241.

2. Green M, Olivier B, Crawley J, Penn D, Silverstein S. Social cognition in schizophrenia: recommendations from the measurement and treatment research to improve cognition in schizophrenia new approaches conference. Schizophr Bull 2005;31:882-887.

3. Wynn J, Sergi M, Dawson M, Schell A, Green M. Sensorimotor gating, orienting and social perception in schizophrenia. Schizophr Res 2005; 73:319-325

4. Kopelowicz A, Liberman RP, Zarate R. Recent advances in social skills training for schizophrenia. Schizophr Bull 2006;32(Suppl 1):S12-S23.

5. Park KM, Ku J, Choi SH, Jang HJ, Park JY, Kim SI, et al. A virtual reality application in role-plays of social skills training for schizophrenia: a randomized, controlled trial. Psychiatry Res 2011;189:166-172.

6. Yalom ID, Leszcz M. The Theory and Practice of Group Psychotherapy (5th Ed.). New York: Basic Books; 2005.

7. Cialdini RB, Goldstein NJ. Social influence: compliance and conformity. Ann Rev Psychol 2004;55:591-621.

8. Chartrand TL, Bargh JA. The chameleon effect: the perception-behavior link and social interaction. J Pers Soc Psychol 1999;76:893-910.

9. Hooley JM. Social factors in schizophrenia. Curr Dir Psychol Sci 2010; 19:238-242.

10. American Psychiatric Association. Diagnostic and Statistical Manual of Mental Disorder, Fourth Edition, Text Revision (Fourth Edition, Text Revision Ed.). Washington, DC: American Psychiatric Association; 2000.

11. Kay SR, Fiszbein A, Opler LA. The Positive and Negative Syndrome Scale (PANSS) for schizophrenia. Schizophr Bull 1987;13:261-276.

12. van der Gaag M, Hoffman T, Remijsen M, Hijman R, de Haan L, van Meijel B, et al. The five-factor model of the Positive and Negative Syndrome Scale II: A ten-fold cross-validation of a revised model. Schizophr Res 2006;85:280-287.

13. Cho NH. The Survey of Usage Frequency of Modern Korean Language. Seoul: The National Academy of Korean Language; 2002.

14. Horvath A, Greenberg L. Development and validation of the Working Alliance Inventory. J Counsel Psychol 1989;36:223-233.

15. Fenigstein A, Vanable P. Paranoia and self-consciousness. J Pers Soc 
Psychol 2006;62:129-138.

16. Tafarodi RW, Kanf SJ, Milne AB. When different becomes similar: compensatory conformity in bicultural visible minorities. Pers Soc Psychol Bull 2002;28:1131-1142.

17. Stangor C, Sechrist GB, Jost JT. Social Influence and Intergroup Beliefs: the Role of Perceived Social Consensus. In: Forgas JP \& Williams KD, Editors. Social Influence: Direct and Indirect Processes, The Sydney Symposium of Social Psychology. New York, NY: Psychology Press, 2001, p.235-252.

18. Kim HS, Markus HR. Deviance or uniqueness, harmony or conformity? A cultural analysis. J Pers Soc Psychol 1999;77:785-800.

19. Nail PR, MacDonald G, Levy DA. Proposal for a four-dimensional model of social response. Psychol Bull 2000;126:454-470.

20. Blanton H, Christie C. Deviance regulation: a theory of identity and action. Rev Gen Psychol 2003;7:115-149.

21. Pool GJ, Wood W, Leck K. The self-esteem motive in social influence: agreement with valued majorities and disagreement with derogated minorities. J Pers Soc Psychol 1998;75:967-975.

22. Brewer MB, Roccas S. Individual Values, Social Identity, and Optimal Distinctiveness. In: Sedikides C, Brewer MB, Editors. Individual, Self, Relational Self, Collective Self. Philadelphia, PA: Psychology Press, 2001, p.219-237.

23. Werner P, Aviv A, Barak Y. Self-stigma, self-esteem and age in persons with schizophrenia. Intern Psychogeriatr 2008;20:174-187.

24. Lysaker PH, Vohs JL, Tsai J. Negative symptoms and concordant impairments in attention in schizophrenia: Associations with social functioning, hope, self-esteem and internalized stigma. Schizophr Res 2009;110:165-172.

25. Selten JP, van der Ven E, Rutten BPF. Cantor-Graae E. The social defeat hypothesis of schizophrenia: an update. Schizophr Bull 2013;39:11801186.
26. David B, Turner JC. Majority and Minority Influence: A Single Process Self-Categorization Analysis. In: De Dreu CKW, De Vries NK, Editors. Group Consensus and Minority Influence: Implications for Innovation. Malden, MA: Blackwell, 2001, p.91-121.

27. Alvaro EM, Crano WD. Indirect minority influence: evidence for leniency in source evaluation and counterargumentation. J Pers Soc Psychol 1997;72:949-964.

28. Postmes T, Spears R, Sakhel K, De Groot D. Social influence in computer-mediated communication: the effects of anonymity on group behavior. Pers Soc Psychol Bull 2001;27:1243-1254.

29. Hutton SB, Murphy FC, Joyce EM, Rogers RD, Cuthbert I, Barnes TR, et al. Decision making deficits in patients with first-episode and chronic schizophrenia. Schizophr Res 2002;55:249-257.

30. Baas D, Aleman A, Vink M, Ramsey NF, de Haan EH, Kahn RS. Evidence of altered cortical and amygdala activation during social decisionmaking in schizophrenia. Neuroimage 2008;40:719-727.

31. Park IH, Park HJ, Chun JW, Kim EY, Kim JJ. Dysfunctional modulation of emotional interference in the medial prefrontal cortex in patients with schizophrenia. Neurosci Lett 2008;440:119-124.

32. Minzenberg MJ, Laird AR, Thelen S, Carter CS, Glahn DC. Meta-analysis of 41 functional neuroimaging studies of executive function in schizophrenia. Arch Gen Psychiatry 2009;66:811-822.

33. Epley N, Gilovich T. Just going along: Nonconscious priming and conformity to social pressure. J Exp Soc Psychol 1999;35:578-589.

34. Pendry L, Carrick R. Doing what the mob do: priming effects on conformity. Eur J Soc Psychol 2001;31:83-92.

35. Klucharev V, Hytönen K, Rijpkema M, Smidts A, Fernández G. Reinforcement learning signal predicts social conformity. Neuron 2009;61:140-151.

36. Martin EA, Becker TM, Cicero DC, Kerns JG. Examination of affective and cognitive interference in schizophrenia and relation to symptoms. J Abnorm Psychol 2013;122:733-744. 